\title{
Pembuatan Prototipe Alat Ukur Ketinggian Air Laut Menggunakan Sensor Inframerah Berbasis Mikrokontroler Atmega328
}

\author{
Azhari $^{1)}$, M. Ishak Jumarang ${ }^{1)} *$ dan Abdul Muid ${ }^{1)}$ \\ ${ }^{1)}$ Jurusan Fisika Fakultas Matematika dan Ilmu Pengetahuan Alam \\ Universitas Tanjungpura \\ *Email : ishakjumaranng@yahoo.com
}

\begin{abstract}
Abstrak
Telah dibangun sebuah prototipe alat untuk mengukur ketinggian permukaan air laut berbasis mikrokontroler ATMega328. Sistem pengukuran berdasarkan prinsip kerja pelampung dan sensor inframerah sehingga dapat mengukur ketinggian permukaan air laut secara langsung. Instrumen ini dapat merekam hasil pengukuran ke dalam media penyimpanan data Multi Media Card (MMC). Tahapan penelitian meliputi proses perancangan, pembuatan dan pengujian alat. Alat ini dirancang untuk mengukur ketinggian air laut pada jarak $15 \mathrm{~cm}$ sampai dengan $110 \mathrm{~cm}$ dari sensor. Hasil eksperimen menunjukkan bahwa kinerja alat dipengaruhi oleh kestabilan gerak pelampung. Hasil pengujian alat memiliki nilai akurasi rata-rata sebesar 99,89\%.
\end{abstract}

Kata kunci : sensor inframerah, mikrokontroler, ketinggian air laut.

\section{Pendahuluan}

Perairan Indonesia sering dijumpai fenomena fisis seperti gerak naik turunnya permukaan air laut secara periodik yang disebut dengan pasang surut (pasut). Pengukuran tinggi permukaan air laut telah banyak dilakukan dengan berbagai macam alat ukur seperti yang telah dilakukan oleh Feri Irawan (2010). Dalam penelitiannya, Feri membangun sebuah instrumen sederhana untuk mengukur gelombang laut berdasarkan prinsip kerja dari pelampung. Data pengukuran yang dihasilkan berupa ketinggian gelombang laut. Sedangkan untuk melihat ketinggian permukaan air laut dilakukan dengan cara menghitung nilai rata-rata tinggi rendahnya gelombang laut dalam tiap satu periode. Selain itu operator dapat memantau ketinggian gelombang laut secara langsung pada tampilan software instrumen.

Perkembangan teknologi di bidang elektronik memungkinkan untuk merancang dan membuat alat ukur ketinggian permukaan air laut tanpa pengamatan langsung. Dalam penelitian ini dibangun sebuah alat yang dapat mengukur ketinggian pelampung di atas permukaan air laut menggunakan sensor inframerah. Untuk menjaga kestabilan pelampung dari pengaruh gelombang laut dilakukan dengan memasukkan pelampung ke dalam paralon. Hasil pengukuran dapat diambil dari proses perekaman yang menggunakan media penyimpan data berupa Multi Media Card (MMC), sehingga operator tidak perlu mengamati hasil pengukuran secara langsung. Selanjutnya data yang telah di simpan ke MMC tersebut dapat digunakan untuk dianalisis jenis pasang surutnya.

\section{Landasan Teori}

\subsection{Pasang Surut}

Pasang surut air laut merupakan proses naik dan turunnya permukaan air laut secara periodik yang ditimbulkan oleh adanya gaya tarik menarik dari benda-benda angkasa, terutama disebabkan oleh gaya tarik Matahari dan gaya tarik Bulan terhadap massa air di permukaan Bumi, serta adanya gaya gravitasi oleh Bumi.

Berdasarkan pada periode dan keteraturannya, pasang surut air laut dapat dibedakan menjadi tiga jenis, yaitu (Tanto, 2009) :

a) Pasang surut harian tunggal (diurnal tide) adalah keadaan yang dalam satu hari terjadi satu kali air pasang dan satu kali air surut, periode pasang surut rata-rata adalah 24 jam 50 menit.

b) Pasang surut harian ganda (semidiurnal tide) adalah keadaan yang dalam satu hari terjadi dua kali air pasang dan dua kali air surut dengan tinggi yang hampir sama dan pasang surut terjadi secara berurutan dan teratur. Periode pasang surut rata-rata adalah 12 jam 25 menit.

c) Pasang surut campuran, terbagi atas dua macam, yaitu:

i. Pasang surut campuran dominan tunggal adalah keadaan yang dalam satu hari terjadi satu kali air pasang dan satu kali air surut, tetapi kadang-kadang untuk sementara waktu terjadi dua kali pasang dan dua kali surut dengan tinggi dan periode yang sangat berbeda.

ii. Pasang surut campuran dominan ganda adalah keadaan yang dalam satu hari terjadi dua kali air pasang dan dua kali air surut, tetapi kadang-kadang untuk sementara waktu terjadi satu kali pasang dan satu kali surut dengan tinggi dan periode berbeda. 
a) Pasang surut harian tunggal

Jakarta (Sunda Kelapa)

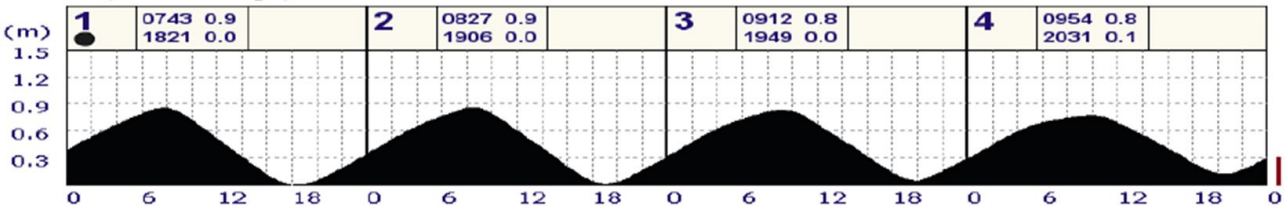

b) Pasang surut harian ganda

Padang (Teluk Bayur)

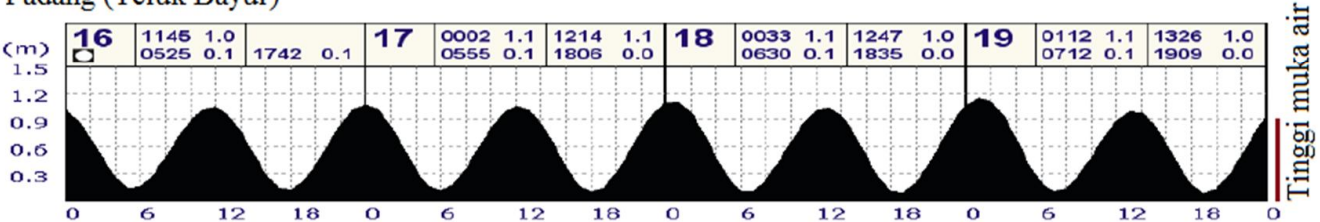

c) Pasang surut campuran

1) Pasang surut campuran dominan tunggal Ambon

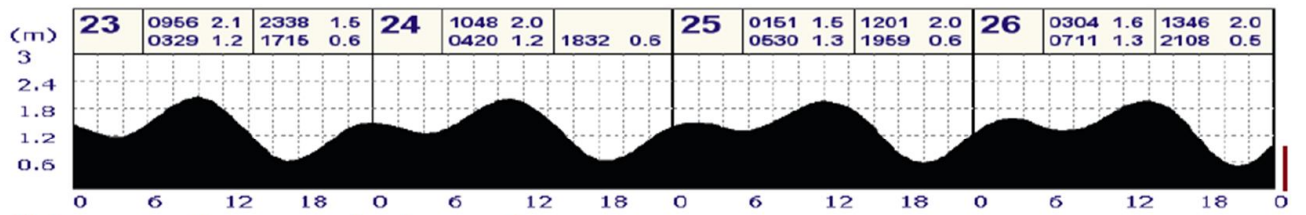

2) Pasang surut campuran dominan ganda

Tahuna

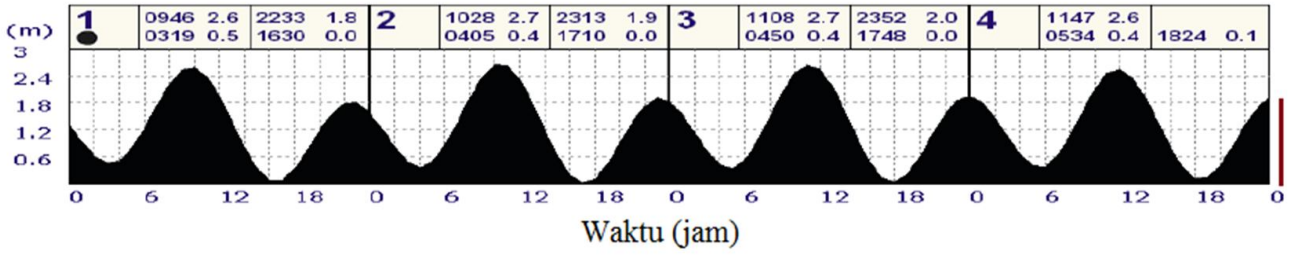

Gambar 1 Tipe-tipe pasang surut

(Sumber : BAKOSURTANAL, 2014)

Pencatatan pasang surut dapat dilakukan secara non registering, yaitu dengan pengamatan langsung untuk mengukur dan mencatat tinggi pasut dari papan ukur yang disebut tide staff, atau pengukuran secara self registering, yaitu pencatatan pasut secara otomatis dengan alat automatic gauge baik berbentuk grafik, punched tape, atau foto (Fitriyanti, 2000). Instrumen pengukur pasang surut yang umum digunakan adalah tide staff, floating tide gauge, dan pressure tide gauge (Adityayuda, 2012).

\subsection{Mikrokontroler ATMega328}

Mikrokontroler merupakan suatu sistem rangkaian mikroprosesor yang terdiri atas CPU, memori internal, rangkaian detak internal dan terminal I/O (Johansyah, 2011). ATMega328 adalah mikrokontroler CMOS (Complement Metal Oxide Semiconductor) 8-bit berarsitektur AVR RISC (Alf and Vegard's Risc Processor) yang memiliki 32 Kbyte in-System Programmable Flash. Mikrokontroler dengan komsumsi daya rendah ini mampu melakukan instruksi dengan kecepatan maksimum 16 MIPS (million instructions per second) pada frekuensi $16 \mathrm{MHz}$ (Purnama, 2011). Bentuk fisik dari IC ATMega328 dapat dilihat pada gambar 2.

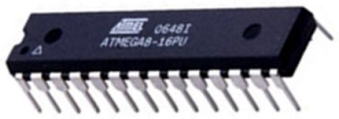

Gambar 2 IC ATMega328

(Sumber : datasheet ATMega328)

\subsection{Sensor Jarak GP2Y0A02YK0F}

GP2Y0A02YK0F adalah salah satu sensor jarak dengan menggunakan media inframerah yang mana sensor ini dapat mendeteksi objek dengan rentang $20 \mathrm{~cm}$ sampai dengan $150 \mathrm{~cm}$, bentuk output dari sensor GP2Y0A02YK0F adalah tegangan analog. Gambar 3 merupakan bentuk dari sensor jarak inframerah GP2Y0A02YK0F.

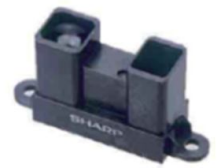

Gambar 3 Sensor GP2Y0A02YK0F (Sumber : datasheet GP2Y0A02YK0F) 
Sensor inframerah ini tidak menghitung waktu pancaran sinar melainkan menghitung pada bagian mana sinar inframerah yang dikembalikan kemudian diterima oleh rangkaian phototransistor. Semakin jauh jarak maka semakin ke kanan sinar inframerah yang diterima pada rangkaian phototransistor dan semakin kecil tegangan outputnya. Hasil output ini akan diterima oleh ADC terlebih dahulu sebelum diambil oleh mikrokontroler.

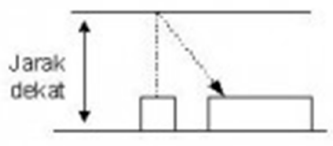

Gambar 4 Pantulan sinar inframerah (Sumber : datasheet GP2Y0A02YK0F)

GP2Y0A02YK0F bekerja pada tegangan dari 4,5 volt sampai 5,5 volt dengan panjang gelombang inframerah sebesar $(\lambda=850 \pm 70 \mathrm{~nm})$. Untuk mendapatkan pengukuran yang valid, diperlukan waktu kurang lebih $5 \mathrm{~ms}$ dari pengukuran pertama ke pengukuran kedua. Sedangkan waktu start up agar sistem stabil membutuhkan waktu $(\mathrm{t}=16,5 \pm 3,7 \mathrm{~ms})$. Ini penting untuk diketahui karena kegagalan pengukuran dapat disebabkan oleh kesalahan melakukan pengukuran ketika sensor dalam keadaan tidak stabil. Gambar 5 merupakan grafik perbandingan antara jarak ukur dengan tegangan output.

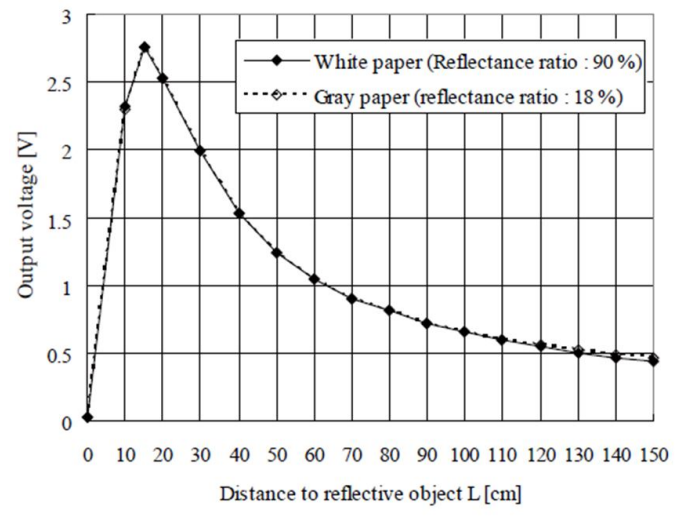

Gambar 5 Grafik Perbandingan Jarak Ukur Dengan Tegangan Output

(Sumber : datasheet GP2Y0A02YK0F)

\subsection{Multi Media Card (MMC) dan Secure Digital Card (SD Card)}

MMC atau SD card merupakan media penyimpanan data yang biasa digunakan pada portable device. SD card merupakan pengembangan dari MMC. Tidak banyak perbedaan antara SD card dengan MMC, diantaranya adalah (Nurwansyah, $d k k, 2009$ ): a. Ukuran SD card lebih tebal dari MMC.

b. SD card memiliki switch untuk write protection, sedangkan MMC tidak. Gambar 6 ini merupakan gambar SD card dan MMC.

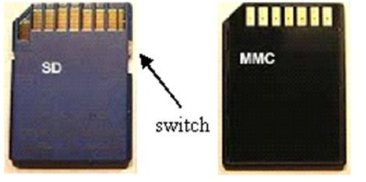

Gambar 6 SD card dan MMC

c. SD card memiliki 9 pin, sedangkan MMC memiliki 7 pin. Susunan pin dari SD card dan MMC dapat dilihat pada Gambar 7.

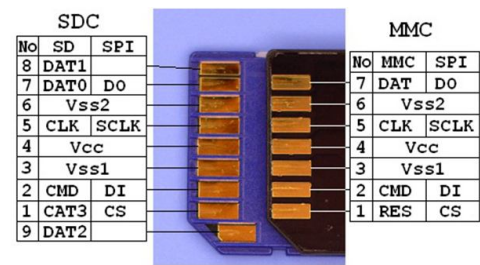

Gambar 7 Konfigurasi pin SD Card dan MMC

(Sumber : Nurwansya, $d k k, 2009$ )

d. SD card memiliki 3 mode transfer data, yaitu mode SD, mode MMC, dan mode SPI (Serial Peripheral Interface). Sedangkan MMC hanya memiliki 2 mode transfer data, yaitu mode MMC dan mode SPI.

e. Kecepatan maksimum transfer data SD card adalah $25 \mathrm{Mbit} / \mathrm{s}$, lebih cepat dari MMC yang memiliki kecepatan maksimum $20 \mathrm{Mbit} / \mathrm{s}$ dengan mode komunikasi yang sama yaitu mode SPI atau mode MMC. Sedangkan pada mode SD kecepatan transfer data maksimum pada SD card dapat mencapai $100 \mathrm{Mbit} / \mathrm{s}$.

\subsection{Real Time Clock (RTC) DS1307}

Real Time Clock (RTC) merupakan serial RTC dengan konsumsi daya rendah yang menyediakan waktu dan penanggalan dalam format BCD (binary-coded decimal) dan memiliki SRAM untuk penyimpanan data sebesar 56 byte. DS1307 diakses dengan metode komunikasi serial sinkron melalui jalur I2C. Gambar 8 merupakan bentuk dari IC DS1307 (Fatoni, $d k k, 2013$ ).

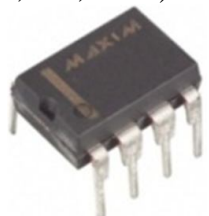

Gambar 8 IC DS1307

(Sumber : Fatoni, $d k k, 2013$ )

\subsection{Liquid Crystal Display (LCD) M1632}

M1632 merupakan modul LCD matrix dengan konfigurasi 16 karakter dan 2 baris dengan setiap karakternya dibentuk oleh 8 baris pixel dan 5 kolom pixel (1 baris pixel terakhir adalah kursor). 
HD44780 ini sudah tersedia dalam Modul M1632 yang dikeluarkan oleh Hitachi, Hyundai dan modul-modul M1632 lainnya (Afniza, 2010).

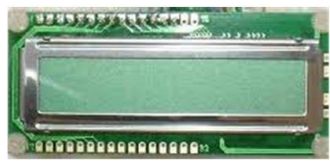

Gambar 9 LCD M1632

(Sumber : Yusuf, 2009)

HD44780 merupakan mikrokontroler yang dirancang khusus untuk mengendalikan LCD dan mempunyai kemampuan untuk mengatur proses scanning pada layar LCD yang terbentuk oleh 16 COM dan 40 SEG sehingga mikrokontroler atau perangkat yang mengakses modul LCD ini tidak perlu lagi mengatur proses scanning pada layar LCD. (Afniza, 2010).

\section{Metodologi}

\subsection{Perancangan Alat}

Sistem pengukuran ketinggian air laut terbagi menjadi beberapa bagian. Bagian pertama yaitu bagian pelampung yang dapat bergerak sesuai dengan ketinggian permukaan air laut dan juga dapat memantulkan sinar inframerah. Sedangkan bagian kedua merupakan bagian elektronik yang dapat mengolah data analog ke dalam bentuk data digital. Selanjutnya data digital tersebut ditampilkan pada LCD dan langsung disimpan ke dalam media penyimpan data berupa MMC. Data yang tersimpan di MMC tersebut akan diolah menggunakan program pengolah data. Gambar 10 merupakan diagram blok sistem dari perancangan alat.

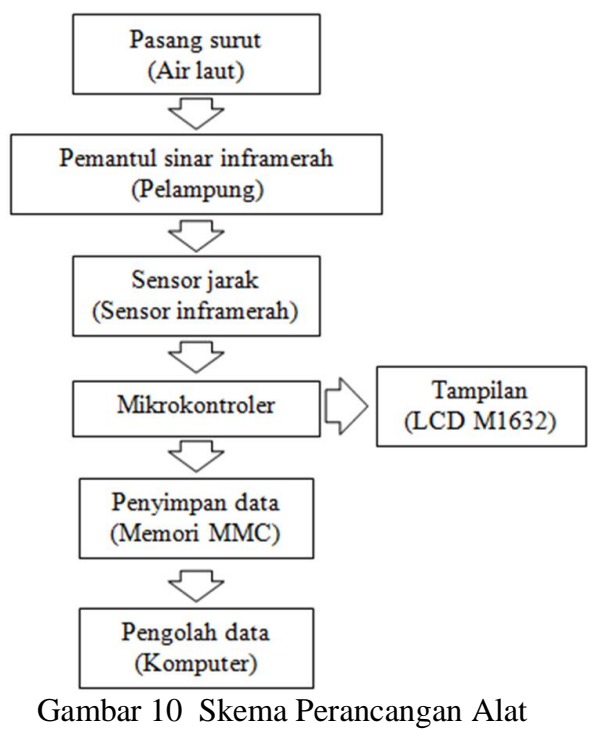

\subsection{Perancangan Perangkat Lunak}

Perancangan perangkat lunak ini merupakan alur dari kode program yang akan dibuat agar sistem dapat bekerja dengan baik, sesuai dengan alur kerja sistem yang telah dibuat.

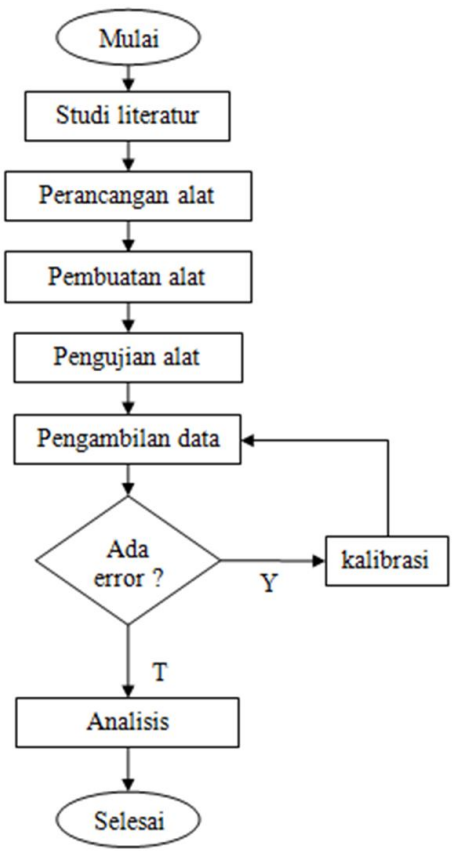

Gambar 11 Diagram Perancangan Perangkat Lunak

\subsection{Cara Kerja Sistem}

Sistem akan bekerja ketika rangkaian telah mendapatkan sumber tegangan dari baterai. Berikut penjelasan cara kerja sistem.

a Langkah pertama ; ketika sistem mendapatkan sumber tegangan maka mikrokontroler akan melakukan inisialisasi dan mengkonfigurasi menggunakan display, port, sensor, maupun MMC serta mendeklarasikan beberapa variabel pendukung untuk proses buffering data.

b Langkah selanjutnya sistem akan menunggu perintah penekanan tombol start yang menandakan proses pengukuran ketinggian air laut telah berkerja sehingga data hasil pengukuran akan tersimpan di MMC serta menampilkanya pada LCD M1632.

c Mikrokontroler akan mengambil data ketinggian permukaan air laut dengan selang waktu selama 5 menit sekali.

d Proses penyimpanan data ketinggian air laut pada MMC dengan format tabel yang berisikan tanggal, waktu dan ketinggian dalam satuan $\mathrm{cm}$.

e Proses akan kembali ke poin c dan menunggu perintah stop. Ketika tombol stop ditekan maka mikrokontroler akan restart.

\section{Hasil dan Pembahasan}

\subsection{Hasil Perancangan Alat}

Alat pengukur ketinggian air laut ini terdiri dari bagian pelampung dan elektronik. Bagian pelampung terdiri dari pemantul sinar inframerah dan tabung pelindung gerakan pelampung. Sedangkan bagian elektronik ini terdiri dari mikrokontroler, LCD, sensor jarak, RTC dan 
media penyimpanan data berupa MMC. Pengujian perangkat alat ukur perlu dilakukan untuk mengetahui kinerja dari masing-masing bagian pelampung dan perangkat elektronik. Gambar 12 merupakan hasil perancangan alat.

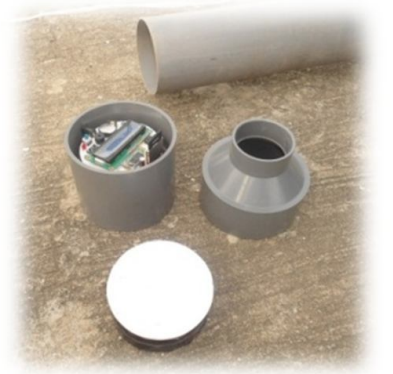

Gambar 12 Perangkat alat bagian pelampung dan bagian elektronik

\subsection{Pengujian pelampung}

Beberapa pengujian telah dilakukan pada sistem pengukuran ketinggian air. Dimana hasilnya diketahui bahwa pelampung dapat bergerak sesuai tinggi permukaan air. Adapun yang harus diperhatikan dalam pembuatan pelampung ini yaitu besarnya diameter pelampung harus mendekati besarnya diameter lubang tabung paralon. Sehingga posisi pelampung diharapkan dalam keadaan stabil atau tidak bergoyang namun dapat bergerak naik turun sesuai permukaan air laut. Selain itu tinggi semua sisi pelampung harus sama, sehingga peletakan bidang permukaan pemantul sinar inframerahnya tidak miring dan dapat memantulkan sinar inframerah dengan akurat.

\subsection{Pengujian Sensor Jarak}

Pengujian sensor jarak berfungsi untuk mengetahui kinerja dari sensor yang berhubungan dengan pengukuran ketinggian permukaan air laut. Pengujian sensor jarak dilakukan dengan cara mengukur ketinggian air dalam bak menggunakan sensor ini. Percobaan dilakukan beberapa kali dengan memvariasikan ketinggian air dalam bak. Hasil pengukuran yang terbaca oleh alat ini kemudian dibandingkan dengan hasil yang terbaca pada meteran.

Dari hasil pengujiannya diketahui sensor ini dapat mengukur dengan tingkat akurasi yang baik. Namun pengujian pada pengukuran lebih dari 120 $\mathrm{cm}$ perlu dilakukan berulang kali, karena perbedaan tegangan output sensor ini sangat kecil pada jarak pengukuran antara $120 \mathrm{~cm}$ sampai dengan $150 \mathrm{~cm}$. Sehingga arus dari sumber tegangan yang kurang stabil dapat mempengaruhi hasil pengukuran sensor ini. Maka dari itu penggunaan sensor jarak pada bagian perangkat alat ini masih perlu ditingkatkan lagi, yaitu dengan menggunakan sensor jarak jenis lainnya yang tingkat akurasinya lebih baik. Dari Gambar 13 menunjukkan bahwa sensor jarak dapat bekerja dengan baik dan memiliki tingkat akurasi sebesar $99 \%$.

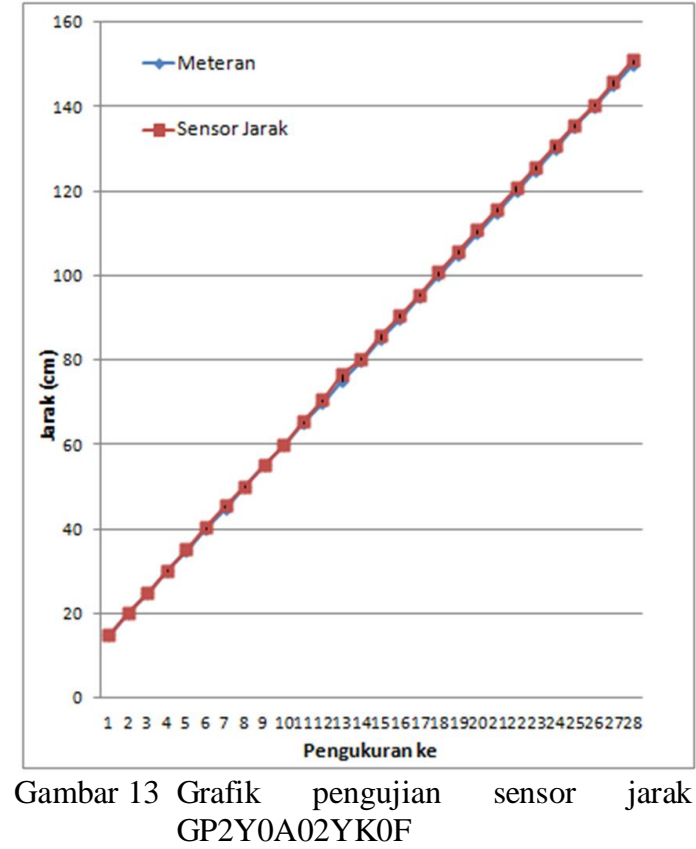

\subsection{Pengujian Sensor Waktu}

Pengujian sensor ini meliputi pengaturan nilai awal dari waktu dan tanggal pada sensor serta hasil pengujian sensor tersebut pada tampilan LCD. Kode program pembacaan data waktu dan tanggal pada RTC DS1307 menggunakan bahasa pemograman $\mathrm{C}$ dengan kompiler arduino IDE.

Pada pengujiannya diketahui sensor ini harus terpasang dengan sumber tegangan khusus yaitu terhubung langsung dengan baterai CMOS. Jika baterai ini terlepas atau tidak terhubung lagi dengan sensor maka semua data variabel waktu dan tanggal akan kembali ke pengaturan awal sensor. Maka dari itu RTC perlu diprogram ulang sesuai dengan waktu dan tanggal yang telah ditentukan. Dari Gambar 14 diketahui bahwa perangkat RTC DS1307 dapat beroperasi dengan baik. Sensor ini dapat menampilkan tanggal dan waktu sesuai dengan waktu pelaksanaan pengujianıya, sehingga dapat dihubungkan pada sistem pengukuran.

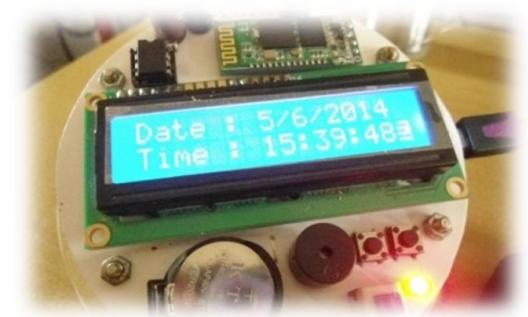

Gambar 14 Hasil Pengujian Sensor Waktu

\subsection{Pengujian MMC}

Pengujian perangkat media penyimpanan data menggunakan MMC, dimana pengujian ini menggunakan perangkat komputer untuk melihat hasil penyimpanan datanya. Dengan melihat hasil pengujian tersebut diketahui MMC dapat 
menyimpan data dalam bentuk file notepad dengan format (txt.), sehingga data pengukuran dapat diambil dalam MMC dan diolah menggunakan perangkat komputer. Dari data tersebut diketahui besar ukuran file untuk penyimpanan sebanyak 1000 data pengukuran hanya memerlukan sekitar 26,3 Kbyte. Sedangkan kapasitas penyimpanan data yang digunakan pada penelitian ini adalah 8 Gbyte. Maka dari itu alat penelitan ini dapat menyimpan lebih dari 1000 data pengukuran.

\subsection{Pengujian Sistem Keseluruhan}

Pengujian sistem keseluruhan dilakukan untuk mengetahui kinerja alat secara keseluruhan. Pengujian dilakukan dengan jarak jangkauan $20 \mathrm{~cm}$ sampai dengan $80 \mathrm{~cm}$ dari dasar bak air. Proses pengambilan data ketinggian air dilakukan dengan membaca meteran yang ditempelkan pada alat. Penambahan tinggi air dilakukan dengan mengisi bak air menggunakan mesin pompa air. Pengambilan data juga dilakukan pada proses pengurangan tinggi air dengan cara membuka kran bak air.

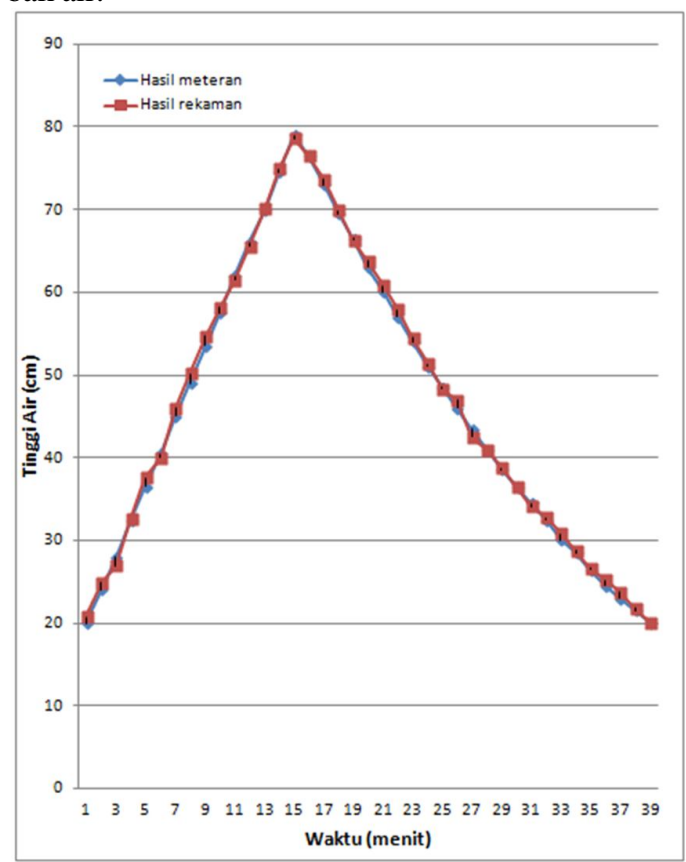

Gambar 15 Grafik data pengamatan pada bak air

Untuk mengetahui tingkat akurasi pengukuran maka perlu dilakukan kalibrasi alat. Kalibrasi alat ini dilakukan untuk mendapatkan nilai kesetaraan antara hasil pengukuran alat yang dibuat dengan nilai pengukuran yang sebenarnya. Cara kalibrasi pada penelitian ini yaitu dengan membandingkan hasil pengukuran yang terbaca oleh alat dengan data ketinggian air yang terbaca oleh meteran. Kalibrasi dilakukan 2 kali yaitu untuk kenaikan dan penurunan permukaan air. a. Pada kenaikan permukaan air

Pengambilan data dilakukan dengan cara menambahkan air pada bak dengan menggunakan pompa air. Kemudian pada saat ketinggian air 20 $\mathrm{cm}$, dimulai pengambilan data. Hasil pengamatan dapat dilihat pada Gambar 16.

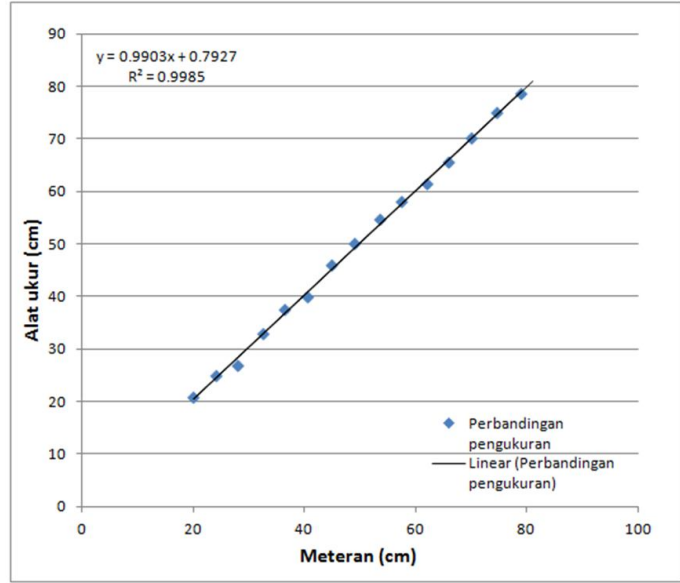

Gambar 16 Grafik Pengukuran Kenaikan Permukaan Air

Berdasarkan grafik pada Gambar 16 diketahui nilai korelasinya adalah 0,9985 . Sehingga nilai tingkat akurasinya adalah 99,85\%.

b. Pada penurunan permukaan air

Pengambilan data dilakukan dengan cara mengurangi air pada bak dengan membuka kran air. Kemudian pada saat ketinggian air $20 \mathrm{~cm}$, pengambilan data dihentikan. Hasil pengamatan dapat dilihat pada Gambar 17.

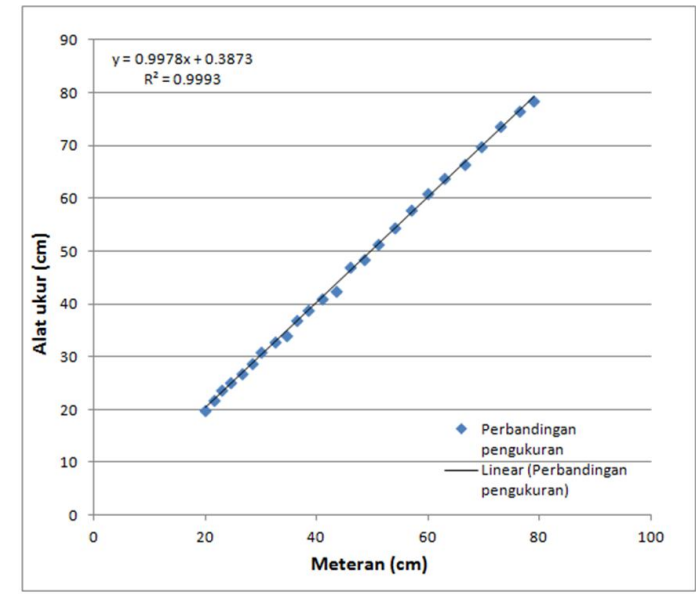

Gambar 17 Grafik Pengukuran Penurunan Permukaan Air

Berdasarkan grafik pada Gambar 17, diketahui nilai korelasinya adalah 0,9993. Sehingga nilai tingkat akurasinya adalah 99,93\%. Dari hasil kedua pengukuran ini diperoleh nilai rata-rata tingkat akurasinya adalah :

$$
\frac{99,85 \%+99,93 \%}{2}=99,89 \% \text {. }
$$


Adapun yang dapat mempengaruhi hasil pengukuran yaitu :

a. Gerakan pelampung tidak stabil (mudah bergoyang) di dalam tabung paralon pada saat naik turunnya permukaan air sehingga dapat menyebabkan pemantulan sinar inframerah kurang akurat. Maka dari itu diameter dan tinggi pelampung perlu diperbesar sehingga kestabilan gerak pelampung dapat dimaksimalkan. Selain itu pelampung perlu diberi pemberat agar gerakannya sesuai dengan permukaan air.

b. Arus listrik dari sumber tegangan yang tidak stabil dapat menyebabkan hasil pengukuran jarak pada sensor inframerah tidak akurat. Maka dari itu perlu adanya alat atau sumber tegangan yang memiliki arus listrik stabil.

c. Pemasangan sensor jarak yang tidak tegak lurus terhadap bidang pemantul sinar inframerahnya dapat menyebabkan simpangan hasil pengukuran bertambah besar. Maka dari itu pemasangan alat ukur pada tabung paralon harus berada pada posisi yang tepat.

Berdasarkan dari semua pengujian yang telah dilakukan, diketahui bahwa semua perangkat dapat berjalan dengan baik dan alat instrumen ini dapat dioperasikan pada pengukuran ketinggian pasang surut air laut.

\section{Kesimpulan}

Berdasarkan penelitian yang telah dilakukan selama proses perancangan, pembuatan, dan pengujian alat ukur ketinggian air laut dapat diketahui beberapa kesimpulan mengenai hasil penelitian sebagai berikut :

a. Alat dapat mengukur ketinggian pasang surut air laut pada jarak $15 \mathrm{~cm}$ sampai dengan $110 \mathrm{~cm}$ dari sensor jarak.

b. Pada pengukuran ketinggian air skala laboratorium, nilai rata-rata tingkat akurasinya adalah $99,89 \%$.

\section{Daftar Pustaka}

Adityayuda, A., 2012, "Pengukuran Faktor Koreksi Jarak Pada Instrumen Motiwali”, Skripsi, Institut Pertanian Bogor, Bogor.

Afniza, 2010, "Pembuatan Alat Ukur Kadar Alkohol Pada Minuman Menggunakan Sensor TGS822 Berbasis Mikrokontroler AVR ATMega8535", Skripsi, Universitas Sumatera Utara, Medan.

BAKOSURTANAL, 2014, "Prediksi Pasang Surut 2014", Bidang Medan Gayaberat dan Pasang Surut, Pusat Geodesi dan Geodinamika, Badan Koordinasi Survei dan Pemetaan Nasional, Cibinong, Bogor.

Fatoni, M., Harianto dan Wibowo, M. C., 2013, "Rancang Bangun Absensi Mahasiswa Menggunakan RFID Dengan Komunikasi Terpusat", Jcones, Vol. II(1): 43-50.

Irawan, F., 2010, "Rancang Bangun Instrumen Pengukur Gelombang Laut Berdasarkan Sistem Pelampung”, Skripsi, Universitas Tanjungpura, Pontianak.

Johansyah, F., Sudjadi dan Arianto, R., 2011, "Kontrol Automatis Fin Stabilizer Pada Kapal Perang Tipe FPB-57 Dengan Berbasiskan Mikrokontroler MC68HC11F1", Skripsi, Universitas Diponegoro, Semarang.

Nurwansyah, E., Andy, A. dan Siang, W., 2009, "MP3 Player Dengan RFID", Skripsi, Universitas Bina Nusantara, Jakarta.

Purnama, I., 2011, "Rancang Bangun Alat Pengukur Laju Kendaraan Berbasis Mikrokontroler ATMega8”, Skripsi, Universitas Komputer Indonesia, Bandung.

Tanto, T. A., 2009, “ Kinerja OTT PS 1 Sebagai Alat Pengukur Pasang Surut Air Laut Di Muara Binuangeun, Provinsi Banten”, Skripsi, Institut Pertanian Bogor, Bogor.

Yusuf, Z., 2009, "Alat Pengaman Jarak Antar Kendaraan Guna Mengurangi Angka Kecelakaan Di Jalan Raya”, Skripsi, Universitas Brawijaya, Malang. 